\title{
Low birthweight in rural Cameroon: an analysis of a cut-off value
}

\author{
Valirie Ndip Agbor ${ }^{*}$, Chobufo Ditah², Joel Noutakdie Tochie ${ }^{3,4}$ and Tsi Njim ${ }^{4,5}$
}

\begin{abstract}
Background: Low birthweight (LBW) is a major predictor of early neonatal mortality which disproportionately affects low-income countries. WHO recommends regional definitions for LBW to prevent misclassifications and ensure appropriate care of babies with LBW. We conducted this study to define a clinical cut-off for LBW, and to determine the predictors and adverse foetal outcomes of LBW babies in a rural sub-division in Cameroon.

Methods: We conducted a retrospective register analysis of 1787 singleton deliveries in two health facilities in the Northwest Region of Cameroon. Records with no birthweight or birthweight less than $1000 \mathrm{~g}$, babies born before arrival, multiple deliveries and deliveries before 28 weeks gestation were excluded from this study. The 10th percentile of birthweights was computed to obtain a statistical cut-off value for the LBW. To assess the clinical significance of the newly defined cut-off value, we compared the prevalence of adverse foetal outcomes between LBW (birthweight $<10$ th percentile) and heavier babies (birthweight $\geq 10$ th percentile) in our study population.

Results: The 10th percentile of the birthweights was $2700 \mathrm{~g}$. Preterm delivery was the lone predictor of LBW $(\mathrm{aOR}=2.0,95 \% \mathrm{Cl}=1.3-3.1 ; p=0.001)$. LBW babies were more likely to be stillborn $(\mathrm{OR}=9.6 ; 95 \% \mathrm{Cl}=4.2-21.6 ; p$ $<0.001)$ or asphyxiated at the 5th minute $(\mathrm{OR}=2.0 ; 95 \% \mathrm{Cl}=1.2-3.3 ; p=0.006)$, compared with heavier babies. Also, 6 . $1 \%$ of babies who had a birthweight between 2500 and $2700 \mathrm{~g}$ were more likely to be stillborn compared to heavier babies.

Conclusion: This study suggests that the clinical cut-off for LBW in this rural community is $2700 \mathrm{~g}$; with $6.1 \%$ of babies born with LBW probably receiving inadequate care as the traditional cut-off value of $2500 \mathrm{~g}$ proposed by WHO is still used to define LBW in our setting. Further studies are necessary to define a national cut-off value for harmonisation of LBW definitions in the country to prevent misclassifications and ensure appropriate neonatal care.
\end{abstract}

Keywords: Cut-off value, Low birthweight, Adverse foetal outcomes, Rural Cameroon

\section{Background}

The World Health Organisation (WHO) defines low birthweight (LBW) as the weight of a neonate below $2500 \mathrm{~g}$ at birth, often corresponding to the 10th percentile for its gestational age [1]. Globally, 20 million neonates are born with LBW, 95\% of whom reside in developing countries [1]. Africa, carries the second highest burden of LBW (14.3\%) after Asia (18.3\%) [1]. LBW babies are about 20fold more likely to develop complications compared with heavier babies. Also, LBW is a major predictor of mortality among infants in low-income countries, especially during the neonatal period [2]. LBW-associated morbidity is

\footnotetext{
* Correspondence: nvagbor@gmail.com

'Ibal Sub-divisional Hospital, Oku, Northwest Region, Bamenda, Cameroon Full list of author information is available at the end of the article
}

further highlighted as it is a significant determinant of failure to thrive, poor cognitive development and chronic diseases in both childhood and adulthood [3, 4]. Globally, LBW is a good indicator of public health problems like chronic maternal illness, malnutrition, hard-work and poor antenatal care [1]. It has become increasingly evident that the traditional cut-off value of $2500 \mathrm{~g}$ advocated by WHO to define LBW may not be generalizable to every settings. For instance, some countries like Sri Lanka with a high incidence of newborns weighing less than $2500 \mathrm{~g}$, do not have an associated high mortality rate [5]. To this effect, WHO has endorsed the definition of a local cut-off value for LBW for every country [1]. However, local data to define LBW in Cameroon, and Africa at large remains meagre. This is worrisome as some babies might not 
receive appropriate care due to misclassification [6]. Njim and colleagues have conducted the lone study so far, in a sub-urban area, to define a practical cut-off for LBW in Cameroon using the 10th percentile [6]. With the aim of contributing to the available body of evidence on LBW in Cameroon, we conducted this study to: define a clinical cut-off for LBW making comparisons with that provided by Njim et al.; and to identify the predictors and adverse outcomes of LBW babies in a rural setting in Cameroon.

\section{Methods}

\section{Study design, duration and settings}

The study methodology has been described in a previous study [7]. Briefly, this was a retrospective register analysis of deliveries conducted between January 1st, 2009 and December 31st, 2016; an 8-year period. This study was conducted in two health facilities: Oku District Hospital and Kevu integrated health centre, in the Oku Subdivision, Northwest Region, Cameroon. These facilities conduct the greater majority of deliveries in this health district. This Sub-division consist of 93,000 inhabitants with farming being the main activity of the people.

\section{Participants and data collection}

All delivery records during the study period were reviewed. Eligible for inclusion were all singleton hospital deliveries. We excluded records with no birthweight or birthweight less than $1000 \mathrm{~g}$, babies born before arrival, multiple deliveries and deliveries before 28 weeks gestation. Out of the 2343 delivery records reviewed, 1787 were retained, giving a response rate of $76.4 \%$.

We collected data on sociodemographic and clinical characteristics of all included mother-neonate pairs which included: age, marital status, gravidity, parity, gestational age, human immunodeficiency virus (HIV) serologic status and gender of the neonate. Foetal outcome parameters such as: birthweight, fifth minute Apgar score, and stillbirth were also collected. Variables were categorised as shown in Table 1. For a comprehensive analysis, parity was categorised into: primiparity - Yes (one previous term delivery) or No (more than one previous term delivery).

\section{Statistical analysis}

Data were entered and analysed using the Statistical Package for Social Sciences (SPSS) version 20.0. Categorical variables are presented as frequencies, proportions and percentages, while continuous variables are presented as means (Standard Deviation) and median (Inter-Quartile Range), where appropriate. The 10th percentile of the birthweights was computed to obtain the cut-off for LBW in our study population. The kappa Cohen coefficient was used to evaluate levels of agreement between the newly defined cut-off, the traditional
Table 1 Definition of operational variables

\begin{tabular}{ll}
\hline Gravidity & 1. Primigravida (Women at their first pregnancy) \\
& 2. Multigravida (2-4 pregnancies) \\
& 3. Grand multigravida ( $>4$ pregnancies) \\
Parity & $\begin{array}{l}\text { 1. Primiparous (Women who had one previous } \\
\text { term delivery) }\end{array}$ \\
& $\begin{array}{l}\text { 2. Multiparous (2-4 previous term deliveries) } \\
\text { 3. Grand multiparous ( }>4 \text { previous term } \\
\text { deliveries) }\end{array}$ \\
Gestational age & $\begin{array}{l}\text { 1. Preterm delivery: Delivery from } 28 \text { to } 36 \text { weeks } \\
\text { of gestation }\end{array}$ \\
& $\begin{array}{l}\text { 2. Term delivery: Delivery from } 37 \text { to } 42 \text { weeks of } \\
\text { gestation }\end{array}$ \\
3. Post-term delivery: Delivery above 42 weeks of \\
gestation
\end{tabular}

cut-off value and the local cut-off proposed by Njim and colleagues [6]. To assess the clinical significance of the newly defined cut-off value, we evaluated the likelihood of LBW babies (babies with birthweights below the newly defined cut-off) to develop adverse foetal outcomes compared with heavier babies. Associations between categorical variables were investigated using the Chi square or Fisher's exact tests where appropriate. The degree of association between the categorical variables was estimated using the odd's ratio (OR) and corresponding 95\% confidence intervals (CI). To determine independent predictors of LBW, a multivariate logistic regression model was built using variables with $p$-values $<0.25$. Two sided p-values less than 0.05 were considered statistically significant.

\section{Ethical considerations}

Ethical approval for the conduct of this study was granted by the Regional delegation of public Health of the Northwest Region of Cameroon and by the directorate of both partaking hospitals.

\section{Results}

Overall, 1787 records were eligible for this study. Maternal ages ranged from 14 to 49 years, with a mean age of $26 \pm 6.5$ years. Over three quarters of women in our study were married by the time of delivery. Also, one quarter of the women were delivering for their first time. There was an equal number of male as female neonates (50.6\% versus $49.4 \%$; Table 2 ). The 10 th percentile for birthweight was equivalent to $2700 \mathrm{~g}$. There was a moderate level of agreement (kappa $=0.54)$ with the traditional cut-off value of $2500 \mathrm{~g}$ proposed by WHO [1]. However, our cut-off strongly agreed $($ kappa $=0.997)$ with the cut-off for LBW reported by Njim et al. in a 
Table 2 Characteristics of the study population

\begin{tabular}{|c|c|c|c|}
\hline \multirow[t]{2}{*}{ Variable } & \multicolumn{2}{|l|}{ Low birthweight } & \multirow{2}{*}{$\begin{array}{l}\text { Total N } \\
(\%)=1787\end{array}$} \\
\hline & Yes, $n=180(\%)$ & No, $n=1607(\%)$ & \\
\hline \multicolumn{4}{|l|}{ Maternal age } \\
\hline Mean (SD) & $25.9(7.5)$ & $26.0(6.5)$ & $26.0(6.5)$ \\
\hline Median (IQR) & $25.0(19.0-32.0)$ & $25.5(21.0-30.5)$ & $\begin{array}{l}25.0(21.0- \\
30.5)\end{array}$ \\
\hline \multicolumn{4}{|l|}{ Marital status } \\
\hline Single & $60(33.5)$ & $374(23.4)$ & $434(24.4)$ \\
\hline Married & $119(66.5)$ & $1226(76.6)$ & $1346(75.6)$ \\
\hline \multicolumn{4}{|l|}{ Gravidity } \\
\hline Primigravida & $65(36.3)$ & $363(23.2)$ & $428(24.5)$ \\
\hline Multigravida & $62(34.6)$ & $782(50.0)$ & $844(48.3)$ \\
\hline Grand multigravida & $52(29.1)$ & $421(26.9)$ & $474(27.2)$ \\
\hline \multicolumn{4}{|l|}{ Parity } \\
\hline Primiparous & $66(36.9)$ & $375(24.0)$ & $441(25.3)$ \\
\hline Multiparous & $63(35.2)$ & $774(49.4)$ & $837(47.9)$ \\
\hline Grand multiparous & $50(27.9)$ & $417(26.6)$ & $468(26.8)$ \\
\hline \multicolumn{4}{|l|}{ Gestational age } \\
\hline Term & $89(54.9)$ & $933(63.4)$ & $1022(62.6)$ \\
\hline Preterm & $69(42.6)$ & $462(31.4)$ & $532(32.6)$ \\
\hline Post term & $4(2.5)$ & $76(5.2)$ & $80(4.9)$ \\
\hline \multicolumn{4}{|l|}{ Maternal HIV status } \\
\hline Positive & $11(6.1)$ & $70(4.4)$ & $81(4.5)$ \\
\hline Negative & 169 (93.9) & 1535 (95.6) & 1705 (95.5) \\
\hline \multicolumn{4}{|l|}{ Gender of infant } \\
\hline Male & $92(52.0)$ & $810(50.5)$ & $902(50.6)$ \\
\hline Female & $85(48.0)$ & 795 (49.5) & $881(49.4)$ \\
\hline
\end{tabular}

HIV Human immunodeficiency virus, $N$ frequency, $S D$ standard deviation, IQR interquartile range

sub-urban Region of Cameroon [6]. After controlling for maternal HIV status, primiparity, maternal age and gender of the infant (Table 3), preterm delivery was the lone predictor of LBW in multivariate analysis [adjusted odd's ratio $(\mathrm{aOR})=1.5 ; 95 \% \mathrm{CI}=1.1-2.2 ; p=0.001$; Table 4]. Also, compared with heavier babies, LBW babies were more likely to be stillborn (OR $=9.6$; $95 \% \mathrm{CI}=4.2-21.6$; $p<0.001)$ or suffer from birth asphyxia at the fifth minute of life $(\mathrm{OR}=2.0 ; 95 \% \mathrm{CI}=1.2-3.3 ; p=0.006)$, Table 5. About $6.1 \%(163 / 1787)$ of babies with birthweights less than $2700 \mathrm{~g}$ were found within the grey zone $(2500$ to $<2700 \mathrm{~g})$. These babies were more likely to be stillborn compared with heavier babies $(\mathrm{OR}=6.4$; 95\% CI $=2.2-18.5 ; p=0.006$; Table 6).

\section{Discussion}

The locally defined clinical cut-off for LBW in this community was found to be $2700 \mathrm{~g}$, with preterm delivery being the lone predictor of LBW. Also, LBW babies were
Table 3 Predictors of low birth-weight on univariate analysis

\begin{tabular}{|c|c|c|c|c|}
\hline Variable & LBW, n (\%) & Total, N & OR (95\% Cl) & $p$-value \\
\hline \multicolumn{5}{|l|}{ Maternal age } \\
\hline$<20$ years & $48(14.0)$ & 365 & $1.6(1.1-2.3)$ & 0.008 \\
\hline$\geq 20$ years & $129(9.1)$ & 1422 & & \\
\hline \multicolumn{5}{|l|}{ Marital status } \\
\hline Single & $58(13.5)$ & 430 & $1.6(1.0-2.7)$ & $0.034^{*}$ \\
\hline Married & $113(8.4)$ & 1343 & & \\
\hline \multicolumn{5}{|l|}{ Primiparity } \\
\hline Yes & $66(15.0)$ & 441 & $1.9(1.3-2.7)$ & $<0.001^{*}$ \\
\hline No & $113(8.7)$ & 1304 & & \\
\hline \multicolumn{5}{|l|}{ Gestational age } \\
\hline Term & $88(8.7)$ & 1022 & & $<0.001^{*}$ \\
\hline Preterm & $69(13.0)$ & 531 & $2.2(1.5-3.2)$ & \\
\hline Post term & $4(5.0)$ & 80 & $0.3(0.1-1.4)$ & \\
\hline \multicolumn{5}{|c|}{ Maternal HIV status } \\
\hline Positive & $11(13.6)$ & 81 & $1.4(0.7-2.7)$ & 0.274 \\
\hline Negative & $169(7.0)$ & 1704 & & \\
\hline \multicolumn{5}{|c|}{ Gender of infant } \\
\hline Female & $85(9.7)$ & 880 & $1.0(0.7-1.4)$ & 0.225 \\
\hline Male & $92(10.2)$ & 902 & & \\
\hline
\end{tabular}

OR Odd's ratio, $\mathrm{Cl}$ Confidence interval, $n$ Frequency, $L B W$ low birthweight,

* significant variables

Table 4 Multivariate analysis of predictors of low birth-weight

\begin{tabular}{lllll}
\hline Variable & LBW, $\mathrm{n}(\%)$ & Total, N & aOR $(95 \% \mathrm{Cl})$ & $p$-value \\
\hline Maternal age & & & & \\
$\quad<20$ years & $48(14.0)$ & 365 & $1.0(1.0-1.1)$ & 0.51 \\
$\begin{array}{l}\text { 20 years } \\
\text { Marital status }\end{array}$ & $129(9.1)$ & 1422 & & \\
$\quad$ Single & $58(13.5)$ & 430 & $0.8(0.5-1.1)$ & 0.180 \\
Married & $113(8.4)$ & 1343 & - & \\
Primiparity & & & & \\
Yes & $66(15.0)$ & 441 & $1.1(0.1-8.4)$ & 0.960 \\
No & $113(8.7)$ & 1304 & - & \\
Gestational age & & & & $0.001^{*}$ \\
Term & $88(8.7)$ & 1022 & - & 0.277 \\
Preterm & $69(13.0)$ & 531 & $1.5(1.1-2.2)$ & \\
Post term & $4(5.0)$ & 80 & $0.6(0.2-1.6)$ & \\
Sex of infant & & & & \\
Female & $85(9.7)$ & 880 & $1.1(0.8-1.5)$ & 0.628 \\
Male & $92(10.2)$ & 902 & - & \\
\hline
\end{tabular}

$a O R$ adjusted odd's ratio, $C I$ Confidence interval, $n$ Frequency, LBW low birthweight, ${ }^{*}$ significant variables 
Table 5 Adverse outcomes of neonates with low birthweight

\begin{tabular}{lcccc}
\hline Variable & LBW, n (\%) & No LBW, n (\%) & OR (95\% Cl) & $p$-value \\
\hline \multicolumn{4}{c}{ Neonatal asphyxia (5th min Apgar) } & \\
Yes, n (\%) & $10(6.0)$ & $45(2.8)$ & $2.2(1.1-4.4)$ & $0.033^{*}$ \\
No, n (\%) & $156(94.0)$ & $1543(97.2)$ & & \\
Still birth & & & & \\
Yes, n (\%) & $12(6.7)$ & $12(0.8)$ & $9.5(4.2-21.5)$ & $<0.001^{*}$ \\
No, n (\%) & $168(93.3)$ & $1594(99.3)$ & & \\
\hline
\end{tabular}

$O R$, Odd's ratio, $C l$ Confidence interval, $n$ Frequency, $L B W$ low birthweight $(<2700 \mathrm{~g}), *$ significant variables

more likely to be stillborn and asphyxiated at birth. More so, babies within the grey zone were more likely to be stillborn compared with heavier babies.

To the best of our knowledge, only one study in subSaharan Africa has defined a local cut-off for LBW [6]. Local cut-off values for LBW have been defined in some developed countries, and ranges from $2750 \mathrm{~g}$ in the US in 1992 [8] to $3000 \mathrm{~g}$ in Denmark in 2007 [9]. Our cutoff for LBW strongly agreed with the 2600 g previous reported by Njim and collaborators in 2015, in sub-urban Cameroon [6]. These results which are similar suggest that the cut-off for LBW in Cameroon proposed by WHO might not be appropriate for use in clinical care, as vulnerable babies within the grey zone (weights $\geq$ $2500 \mathrm{~g}$ but $<2700 \mathrm{~g}$ ) are probably not receiving adequate care as they are rather regarded to have a normal birthweight. In this study, $6.1 \%$ of the babies were found in this grey area. LBW is a significant predictor for neonatal mortality [10]. Such misclassifications are likely contributors to the overall neonatal mortality. Indeed, babies born with birthweights within this grey zone were about six times more likely to be stillborn compared with heavier babies. This emphasises the need for more studies within the country to harmonise LBW definitions for the institution of appropriate public health policies to address the problem.

Preterm delivery was the lone predictor of LBW in this study. This finding is consistent with other reports from

Table 6 Adverse outcome of neonates with birthweight of 2500 to $<2700 \mathrm{~g}$

\begin{tabular}{lllll}
\hline Variable & $\mathrm{BW}_{1}, N=163$ & $\mathrm{BW}_{2}, N=1553$ & $\mathrm{OR}(95 \% \mathrm{Cl})$ & $p$-value \\
\hline $\begin{array}{l}\text { Neonatal asphyxia (5th min Apgar) } \\
\text { Yes, n (\%) }\end{array}$ & $6(11.8)$ & $45(88.2)$ & $2.1(0.9-5.2)$ & 0.126 \\
No, n (\%) & $98(6.0)$ & $1543(94.0)$ & & \\
Still birth & & & & \\
Yes, n (\%) & $5(29.4)$ & $12(70.6)$ & $6.4(2.2-18.5)$ & $0.003^{*}$ \\
No, n (\%) & $104(6.1)$ & $1594(93.9)$ & &
\end{tabular}

$B W_{1}$ Birthweight within the category 2500 to $<2700 \mathrm{~g}, B W_{2}$ Birthweight $\geq 2700 \mathrm{~g}$ $\mathrm{N}$ absolute frequency, $\mathrm{Cl}$ confidence interval, ${ }^{*}$ significant variables
sub-Saharan Africa [6, 11, 12]. It is obvious that preterm infants will have a LBW, as they are not privileged to attain the required term for a normal weight. Preterm deliveries have been associated with poor antenatal care and chronic maternal diseases like HIV [6, 13, 14]. Nevertheless, we found no significant association between being an adolescent, a single mother, a female neonate and LBW. Also, the first pregnancy and delivery, and a positive maternal HIV status did not predict LBW. This finding corroborated with that of Njim et al. [6]. In contrast to observations made by Abubakari et al. [15], we did not find a significant association between primiparity and a female neonate with LBW, probably explained by the fact that the authors did not account for confounders in their study. Finally, LBW was significantly associated with neonatal asphyxia at the 5th minute of life and stillbirth. This finding is consistent with other African series $[6,16]$. This reiterates reports by Koum and colleagues which depict LBW as a major contributor to the early neonatal mortality burden in Cameroon [10], and therefore the need to implement evidence-based measures, like defining a local cut-off value for LBW, to provide appropriate care to these infants. Providing care to LBW babies using evidencebased methods might be key in achieving the third goal of sustainable development [17].

Despite its limitations, birthweight remains a relatively reliable parameter to determine the risk of neonatal mortality. This is especially true in rural communities where the use of first trimester ultrasonography for gestational dating is practically non-existent. However, the records of gestational ages (based on the clients' last menstrual periods) entered into the delivery registers might not be accurate as it is subject to recall bias. The length of the gestation is also crucial in predicting neonatal morbidity and mortality [18], and simply adopting the new cut-off value of $2700 \mathrm{~g}$ for the LBW might have limited value in curbing neonatal morbidity and mortality in these rural communities.

\section{Study limitations}

Being a retrospective study, we had no influence on the quality of data entered into the delivery registers. The risk of other neonatal complications like neonatal infection, admission to the neonatal unit, and hypoglycaemia, for example, could not be evaluated due to unavailability of relevant data. In addition, predictors of LBW such as use of recreational drugs, smoking and alcohol consumption during pregnancy could not be assessed due to lack of data collected on these variables in our delivery registers. This study was not designed to identify constitutional causes of LBW (genetic predisposition), highlighting the need for further research in this domain. However, with the large sample size (1787 newborns) and a robust 
statistical analysis controlling potential confounders, we ruled out several potential biases in the results obtained.

\section{Conclusion}

We have demonstrated that the clinical cut-off for LBW in this rural community is $2700 \mathrm{~g}$, with preterm delivery being the sole determinant of LBW. LBW babies were more likely to be stillborn or asphyxiated at the fifth minute of life. A significant proportion of these babies may be receiving inadequate neonatal care as the traditional cut-off of $2500 \mathrm{~g}$ proposed by the WHO is still used to define LBW in this rural area. However, more data is needed through a prospective study design with larger sample size to define a cut-off value for LBW over the national territory; as this will guide the implementation of effective preventive strategies to curb the morbidity and mortality associated with LBW in Cameroon. While pursuing the validation of a cut-off value for LBW on a larger scale in Cameroon, it is prudent to adopt our current cut-off value for LBW in this rural community.

\section{Abbreviations}

aOR: Adjusted odd's ratio; Cl: Confidence interval; HIV: Human Immunodeficiency Virus; LBW: Low birth weight; OR: Odd's ratio; US: United States; WHO: World Health Organisation

\section{Acknowledgements}

The authors will like to thank the staff of the Oku District Hospital and Kevu primary health centre for their cooperation during the study.

\section{Funding}

None.

\section{Availability of data and materials}

The datasets generated and/or analysed during the current study are available from the corresponding author on reasonable request.

\section{Authors' contributions}

Study conception: VNA; Data collection; VNA: data analysis: CD and TN; Data interpretation: CD, TN, JNT, and VNA; Write up of first manuscript: VNA; Manuscript revision: VNA, CD, JNT and TN. All authors read and approved the final manuscript.

\section{Ethics approval and consent to participate}

Ethical approve was obtained from the scientific and ethical review board of the Northwest Regional delegation for Public Health.

\section{Consent for publication}

Not applicable.

\section{Competing interests}

The authors declare that they have no competing interests.

\section{Publisher's Note}

Springer Nature remains neutral with regard to jurisdictional claims in published maps and institutional affiliations.

\section{Author details}

${ }^{1}$ Ibal Sub-divisional Hospital, Oku, Northwest Region, Bamenda, Cameroon. ${ }^{2}$ Doctors Without Borders-French Section (MSF-F), Calais, France.

${ }^{3}$ Department of Surgery and sub-Specialties, Faculty of Medicine and Biomedical Sciences, University of Yaoundé I, Yaoundé, Cameroon. ${ }^{4}$ Health and Human Development Research Group (2HD), Douala, Cameroon. ${ }^{5}$ Centre for Global Health and Tropical Medicine, Nuffield Department of Medicine, University of Oxford, Oxfordshire, UK.

Received: 28 April 2017 Accepted: 8 January 2018

Published online: 15 January 2018

References

1. Wardlaw TM, World Health Organization, UNICEF, editors. Low birthweight: country, regional and global estimates. Geneva : New York: WHO; UNICEF; 2004.

2. Demelash H, Motbainor A, Nigatu D, Gashaw K, Melese A. Risk factors for low birth weight in Bale zone hospitals, South-East Ethiopia : a case-control study. BMC Pregnancy Childbirth [Internet]. 2015 [cited 2017 Apr 2];15. Available from: http://www.ncbi.nlm.nih.gov/pmc/articles/PMC4604703/

3. Barker DJ. The fetal and infant origins of adult disease. BMJ. 1990;301:1111.

4. Sreeramareddy CT, Chuni N, Patil R, Singh D, Shakya B. Anthropometric surrogates to identify low birth weight Nepalese newborns: a hospitalbased study. BMC Pediatr. 2008;8(16)

5. Pathmanathan I. Investing in maternal health : learning from Malaysia and Sri Lanka [Internet]. The World Bank; 2003 Dec p. 1-206. Report No.: 25901 Available from: http://documents.worldbank.org/curated/en/367761468760748311/ Investing-in-maternal-health-learning-from-Malaysia-and-Sri-Lanka

6. Njim T, Atashili J, Mbu R, Choukem S-P. Low birth weight in a sub-urban area of Cameroon: an analysis of the clinical cut-off, incidence, predictors and complications. BMC Pregnancy Childbirth [Internet]. 2015 [cited 2017 Mar 27];15. Available from: http://www.ncbi.n/m.nih.gov/pmc/articles/ PMC4634914/

7. Agbor VN, Mbanga CM, Njim T. Adolescent deliveries in rural Cameroon: an 8-year trend, prevalence and adverse maternofoetal outcomes. Reprod Health. 2017;14(0):122.

8. Goldenberg RL, Hoffman HJ, Cliver SP, Cutter GR, Nelson KG, Copper RL. The influence of previous low birth weight on birth weight, gestational age, and anthropometric measurements in the current pregnancy. Obstet Gynecol. 1992;79:276-80

9. Rode L, Hegaard HK, Kjaergaard H, Møller LF, Tabor A, Ottesen B. Association between maternal weight gain and birth weight. Obstet Gynecol. 2007;109: 1309-15.

10. Kedy Koum D, Exhenry C, Penda C-I, Nzima Nzima V, Pfister RE. Neonatal morbidity and mortality in a low-resource urban district hospital of Douala, Cameroon. Arch Pediatr. 2014;21:147-56.

11. Oladeinde HB, Oladeinde OB, Omoregie R, Onifade AA. Prevalence and determinants of low birth weight: the situation in a traditional birth home in Benin City. Nigeria Afr Health Sci. 2015;15:1123-9.

12. Muchemi OM, Echoka E, Makokha A. Factors associated with low birth weight among neonates born at Olkalou District Hospital, Central Region, Kenya. Pan African Medical Journal [Internet]. 2015 [cited 2017 Apr 7];20. Available from: http://www.panafrican-med-journal.com/content/article/20/ 108/full/\#.WOfoGvnyvlU

13. Siza JE. Risk factors associated with low birth weight of neonates among pregnant women attending a referral hospital in northern Tanzania. Tanzan J Health Res. 2008;10:1-8.

14. Monebenimp F, Nga-Essono DE, Zoung-Kany Bissek A-C, Chelo D, Tetanye E. HIV exposure and related newborn morbidity and mortality in the university teaching Hospital of Yaoundé, Cameroon. Pan Afr Med J. 2011:8(43)

15. Abubakari A, Kynast-Wolf $G$, Jahn A. Prevalence of abnormal birth weight and related factors in northern region, Ghana. BMC Pregnancy and Childbirth. 2015 15(335)

16. Mitao M, Philemon R, Obure J, Mmbaga BT, Msuya S, Mahande MJ. Risk factors and adverse perinatal outcome associated with low birth weight in northern Tanzania: a registry-based retrospective cohort study. Asian Pacific Journal of Reproduction. 2016:5:75-9.

17. Transforming our world: the 2030 Agenda for Sustainable Development .: Sustainable Development Knowledge Platform [Internet]. [cited 2017 Apr 23]. Available from: https://sustainabledevelopment.un.org/post2015/ transformingourworld

18. Morken N-H, Klungsøyr K, Skjaerven R. Perinatal mortality by gestational week and size at birth in singleton pregnancies at and beyond term: a nationwide population-based cohort study. BMC Pregnancy and Childbirth. 2014;14(172) 